\title{
2-Aminopurine-Modified DNA Homopolymers for Robust and Sensitive Detection of Mercury and Silver
}

\author{
Wenhu Zhou ${ }^{1,2}$, Jinsong Ding ${ }^{1}$ and Juewen Liu ${ }^{1,2} *$ \\ 1. School of Pharmaceutical Sciences, Central South University, Changsha, Hunan, China, \\ 410013. \\ 2. Department of Chemistry, Waterloo Institute for Nanotechnology, University of Waterloo, \\ Waterloo, Ontario, Canada, N2L 3G1. \\ *Email: liujw@uwaterloo.ca
}




\begin{abstract}
Heavy metal detection is a key topic in analytical chemistry. DNA-based metal recognition has advanced significantly producing many specific metal ligands, such as thymine for $\mathrm{Hg}^{2+}$ and cytosine for $\mathrm{Ag}^{+}$. For practical applications, however, robust sensors that can work in a diverse range of salt concentrations need to be developed, while most current sensing strategies cannot meet this requirement. In this work, 2-aminopurine (2AP) is used as a fluorescence label embedded in the middle of four 10-mer DNA homopolymers. 2AP can be quenched up to $98 \%$ in these DNA without an external quencher. The interaction between 2AP and all common metal ions is studied systematically for both free 2AP base and 2AP embedded DNA homopolymers. With such low background, $\mathrm{Hg}^{2+}$ induces up to 14-fold signal enhancement for the poly-T DNA, and $\mathrm{Ag}^{+}$enhances up to 10 -fold for the poly-C DNA. A detection limit of $3 \mathrm{nM}$ is achieved for both metals. With these four probes, silver and mercury can be readily discriminated from the rest. A comparison with other signaling methods was made using fluorescence resonance energy transfer, graphene oxide, and SYBR Green I staining, respectively, confirming the robustness of the 2AP label. Detection of $\mathrm{Hg}^{2+}$ in Lake Huron water was also achieved with a similar sensitivity. This work has provided a comprehensive fundamental understanding of using $2 \mathrm{AP}$ as a label for metal detection, and has achieved the highest fluorescence enhancement for nonprotein targets.
\end{abstract}

Keywords: biosensors; aptamers; DNA; metal ions; fluorescence 


\section{Introduction}

Mercury and silver are toxic heavy metals but they are useful for a diverse range of applications. Their bio-accumulative property poses a severe threat to human health (Clarkson et al. 2003; Ratte 1999). To manage their contamination problem, efforts have been made to develop sensors for their on-site and real-time detection (Kim et al. 2012; Nolan and Lippard 2008), including using monoclonal antibodies (Zhou et al. 2011). These two metals are discussed together here since they are both strongly thiophilic with a similar redox potential, making it a challenge to accurately distinguish them sometimes.

Over the past two decades, DNA has become quite popular for metal sensing (Li et al. 2010; Liu et al. 2009; Wang et al. 2009a; Zhan et al. 2016; Zhang et al. 2011), which is attributable to its stability, programmability, versatile metal coordination chemistry, and ease of modification. For silver and mercury, in particular, a number of DNA-based sensing strategies have been developed. For example, DNAzymes (i.e. catalytic DNA) were isolated using $\mathrm{Hg}^{2+}$ and $\mathrm{Ag}^{+}$as specific metal cofactors for RNA cleavage (Hollenstein et al. 2008; Saran and Liu 2016). In addition, their strong thiophilicity has allowed cleavage of phosphorothioate (PS)modified RNA for biosensor design (Huang and Liu 2014; Huang et al. 2015). The fluorescence of some DNA-stabilized metal nanoclusters can be quenched or shifted by $\mathrm{Hg}^{2+}$ and $\mathrm{Ag}^{+}\left(\mathrm{Lee} \mathrm{et}^{2}\right.$ al. 2015; Morishita et al. 2013; Shiang et al. 2012).

The most popular sensing methods have relied on the specific formation of thymine$\mathrm{Hg}^{2+}$-thymine (Ono and Togashi 2004), and cytosine-Ag+'-cytosine base pairs (Ono et al. 2008). In both cases, the target metal converts $\mathrm{T}-\mathrm{T}$ and $\mathrm{C}-\mathrm{C}$ mismatches to stable base pairs (Li et al. 2008; Li et al. 2009b; Miyake et al. 2006; Ono et al. 2011; Tanaka et al. 2007). These are 
attractive due to reversible metal binding and simplicity. A careful examination of related literature has however identified a few limitations, and here we focus our discussion on fluorescence-based sensors. Some signaling methods rely on end-to-end distance change, where fluorescence resonance energy transfer (FRET) is often used (Ono et al. 2008; Ono and Togashi 2004). This method is highly susceptible to variations in ionic strength, since the end-to-end distance can also be changed by non-specific salt-induced DNA condensation (Kiy et al. 2012). Second, DNA staining dyes such as SYBR Green I were used (Lin and Tseng 2009; Wang and Liu 2008). While simple and cost-effective, it is prone to artifacts (e.g. dye adsorption by other nucleic acids or surfaces), and the dye/DNA binding is also dependent on salt concentration. The third strategy relies on the structure-switching mechanism (Nutiu and Li 2003; Wang et al. 2008), which is difficult to achieve reversible sensing and is likely also sensitive to ionic strength. For practical applications, robust and reversible sensors still need to be designed.

2-Aminopurine (2AP) is a fluorescent adenine analog that has been extensively used for probing nucleic acids (Hall 2009; Jones and Neely 2015). When a 2AP is introduced into a DNA structure, its fluorescence yield decreases significantly because of stacking with adjacent bases. While 2AP is an excellent probe to study DNA folding, its analytical applications have not been extensively explored (Katilius et al. 2006; Li et al. 2009a; Martí et al. 2006; Soulière et al. 2011). A major advantage of $2 \mathrm{AP}$ is strong fluorescence quenching (can reach $>98 \%$ ) without an external quencher (just quenched by adjacent nucleobases) (Jones and Neely 2015). Given these merits, little is known about its interaction with heavy metals. In this work, we designed four DNA homopolymers probes, each with an embedded 2AP. When used together to form a sensor array, they can distinguish $\mathrm{Ag}^{+}$and $\mathrm{Hg}^{2+}$ from the rest with up to 14-fold fluorescence enhancement. 


\section{Materials and Methods}

2.1. Chemicals. All the DNA samples were obtained from Integrated DNA Technologies (Coralville, IA). The metal salts and the free 2AP base were from Sigma-Aldrich. All the buffers were from Mandel Scientific Inc. (Guelph, Ontario, Canada). Milli-Q water was used to prepare all the buffers and solutions.

2.2. Fluorescence spectroscopy. Free 2 AP base or 2 AP-modified DNAs $(1 \mu \mathrm{M})$ were dissolved in buffer A (10 mM MOPS, pH 7.0, adjusted by adding $\mathrm{HNO}_{3}$ and $\mathrm{NaOH}$ ). The fluorescence spectra were measured using a fluorometer (FluoroMax-4, Horiba Scientific) with $310 \mathrm{~nm}$ excitation and the emission at $370 \mathrm{~nm}$ was used for quantification. To measure the effect of metal ions, free $2 \mathrm{AP}$ base or $2 \mathrm{AP}$ modified DNAs $(0.1 \mu \mathrm{M})$ were dissolved in buffer $\mathrm{A}$, and their initial fluorescence spectra were recorded as described above. The fluorescence was measured immediately after adding a small volume of metal salt solution.

2.3. $\mathbf{H g}^{2+} / \mathbf{A g}^{+}$detection. The $2 \mathrm{AP}-$ modified DNA sensors $(0.1 \mu \mathrm{M})$ were dissolved in buffer A. The 2AP fluorescence at $370 \mathrm{~nm}$ was monitored immediately after each addition of $\mathrm{Hg}^{2+}, \mathrm{Ag}^{+}$or other metal ions. To test reversibility, the $\mathrm{Hg}^{2+}$ sensor was added with $400 \mathrm{nM} \mathrm{Hg} \mathrm{Hg}^{2+}$. $\mathrm{After}^{2}$ continuously monitoring for $5 \mathrm{~min}, 800 \mathrm{nM} \mathrm{NaI}$ was added, followed by $5 \mathrm{~min}$ fluorescence reading. The process was repeated for four times. To test the sensor performance in Lake Huron water, $1 \mu \mathrm{L}$ T10-2AP DNA (100 $\mu \mathrm{M})$ and $10 \mu \mathrm{L}$ MOPS (1 M, pH 7.0) were added to $1 \mathrm{~mL}$ Lake Huron water. Then, $200 \mu \mathrm{L}$ of the sample was titrated with $\mathrm{Hg}^{2+}$, and the $2 \mathrm{AP}$ emission was recorded.

2.4. Other $\mathbf{H g}^{2+}$ sensors. To graphene oxide (GO) based probe, 6-carboxyfluorescein labeled $\mathrm{Hg}^{2+}$-binding DNA (4 $\mu \mathrm{M}$, the sequence shown in Figure 4B) was mixed with nano-sized GO 
$(200 \mu \mathrm{g} / \mathrm{mL})$ in buffer B $\left(2 \mathrm{mM} \mathrm{Mg}{ }^{2+}, 50 \mathrm{mM} \mathrm{NaCl}, 10 \mathrm{mM}\right.$ HEPES, pH 7.6). After $30 \mathrm{~min}$ incubation, the sensor was washed after centrifugation at 15,000 rpm for $30 \mathrm{~min}$, and then redispersed in buffer A (with $100 \mathrm{nM}$ adsorbed DNA). Then, the sensor was added with $400 \mathrm{nM}$ $\mathrm{Hg}^{2+}$ in absence or presence of $100 \mathrm{mM} \mathrm{NaNO}$. The fluorescence kinetic was monitored by a SpectraMax M3 microplate reader $(E x=480 \mathrm{~nm} ; \mathrm{Em}=526 \mathrm{~nm})$ for $1 \mathrm{~h}$. For SYBR Green $\mathrm{I}(\mathrm{SG})$ based probe, the $\mathrm{Hg}^{2+}$-binding DNA $(100 \mathrm{nM})$ and SG $(250 \mathrm{nM})$ were diluted in buffer A. In absence or presence of $100 \mathrm{mM} \mathrm{NaNO}_{3}, 400 \mathrm{nM} \mathrm{Hg}^{2+}$ was added, and the fluorescence change was measured by a FluoroMax-4 fluorometer $(E x=480 \mathrm{~nm}$; Em $=515-570 \mathrm{~nm})$. The peak intensity at 525 was used for quantification.

\section{Results and Discussion}

3.1. Mechanism of 2AP signaling. The structures of adenine and 2AP are shown in Figure 1A. They differ only by the position of the exocyclic amine group. Free 2AP emits strongly at 370 nm with a quantum yield of 0.68 (Jones and Neely 2015), while adenine is essentially nonfluorescent. Interestingly, the 2AP fluorescence is strongly quenched after incorporation into an oligonucleotide, attributable to stacking with neighboring nucleobases facilitating electron transfer (Kelley and Barton 1999), and collision by other bases (Rachofsky et al. 2001).

We first systematically studied the interaction between $2 \mathrm{AP}$ and heavy metals. Four probes were designed here, each inserting a $2 \mathrm{AP}$ in the middle of a 10-mer DNA homopolymer (Figure 1B). The fluorescence spectra of the free 2AP base and these four probes at the same concentration are shown in Figure 1C. In a polypyrimidine ( $\mathrm{C}$ and $\mathrm{T}$ ), the $2 \mathrm{AP}$ emitted 4 to 7 fold less compared to that in a polypurine (A and G). Their quenching efficiencies are shown in 
Figure 1D. The T10-2AP DNA reached the highest quenching of $\sim 98 \%$, with the quenching order being $\mathrm{T} \cong \mathrm{C}>\mathrm{A} \cong \mathrm{G}$. Larsen and coworkers used dinucleotides and reported a $2 \mathrm{AP}$ quenching order of $\mathrm{G}>\mathrm{T} \cong \mathrm{A}>\mathrm{C}$ (Larsen et al. 2004). On the other hand, Ross et al showed that 2AP is quenched more by flanking thymines than by adenines, which is consistent with our results (Rachofsky et al. 2001).

Such a strong quenching is very impressive considering the lack of external quenchers. For example, a $98 \%$ quenching compares favorably to that achieved by molecular beacons with a nearby dark quencher (Tyagi and Kramer 1996; Wang et al. 2009b). In our system, quenching is achieved solely by DNA bases. This quenching is also different from the typical fluorophore quenching by DNA. In those cases, guanine is the strongest quencher but it quenches nearby fluorophores by only 2-fold (Nazarenko et al. 2002). Such a strong 2AP quenching gives a large room for potential signal enhancement and thus high sensitivity. 
A<smiles>CCn1cnc2c(N)ncnc21</smiles><smiles>Cn1cnc2cnc(N)nc21</smiles>

B

\begin{tabular}{cc}
\hline Name & DNA sequence \\
\hline A10-2AP & AAAAA2APAAAAA \\
T10-2AP & TTTTT2APTTTTT \\
C10-2AP & CCCCC2APCCCCC \\
G10-2AP & GGGGG2APGGGGG \\
\hline
\end{tabular}
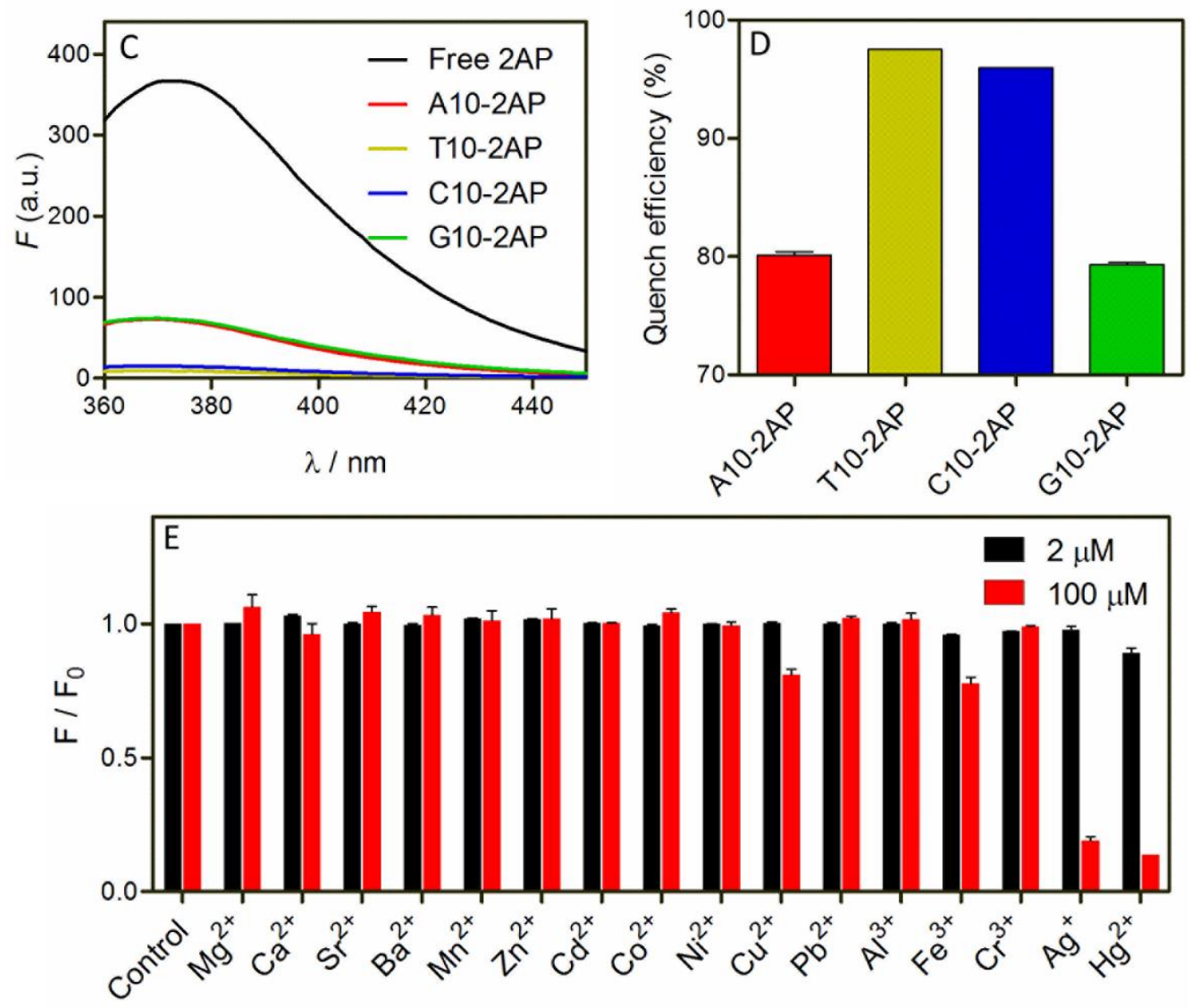

Figure 1. (A) The structures of adenine and 2AP. (B) The names and sequences of the DNAs used in this study. 2AP is inserted in the middle of each sequence. (C) Fluorescence spectra of the free 2AP base, and the four DNAs (1 $\mu \mathrm{M}$ each). (D) Quench efficiency of 2AP in the different DNA sequences. (E) Quench efficiency of the free 2AP base by metal ions. 
3.2. Quenching of free $2 \mathrm{AP}$ by metal ions. Before testing our DNA probes, we mixed various metal ions with the free $2 \mathrm{AP}$ base. With $2 \mu \mathrm{M}$ metals (Figure $1 \mathrm{E}$, black bars), only $\mathrm{Hg}^{2+}$ caused $\sim 10 \%$ quenching. This suggests a relatively low binding affinity between the metal ions and free 2AP. With $100 \mu \mathrm{M}$ metals ( $2 \mathrm{mM}$ for $\mathrm{Mg}^{2+}$ and $\left.\mathrm{Ca}^{2+}\right), \mathrm{Hg}^{2+}$ still yielded the strongest quenching of $86 \%$ (Figure 1E, red bars), followed by $\mathrm{Ag}^{+}(\sim 80 \%)$ and $\mathrm{Cu}^{2+}$ and $\mathrm{Fe}^{3+}(\sim 20 \%)$. Most other metals again failed to quench. It is interesting to note that the ability to quench the $2 \mathrm{AP}$ emission correlates well with the thiophilicity of the metals, suggesting specific binding. Overall, nonspecific quenching of $2 \mathrm{AP}$ by the metals is quite low. At the same time, no fluorescence enhancement was observed.

3.3. Emission enhancement by $\mathbf{H g}^{2+}$ and $\mathbf{A g}^{+}$. We next titrated various metal ions to each of the four DNA probes. Since each probe has a different initial fluorescence (Figure 1C), we plotted the relative fluorescence change $\left(F / F_{0}\right)$ after adding metal. Addition of $2 \mu \mathrm{M}$ metals to the A10-2AP DNA $(0.1 \mu \mathrm{M})$ caused $<10 \%$ fluctuation in most cases (Figure $2 \mathrm{~A}$ ). The most significant quenching occurred with $\mathrm{Ag}^{+}(\sim 20 \%)$ and $\mathrm{Hg}^{2+}(\sim 30 \%)$. Since the free $2 \mathrm{AP}$ base was quenched much less (Figure 1E), DNA binding to these metals also contributes to the quenching. The G10-2AP DNA is more susceptible to metal-induced quenching (Figure 2B). In these two DNAs, metal binding might induce electron transfer to paramagnetic metals (e.g. $\mathrm{Cu}^{2+}$ ) or enhance stacking of $2 \mathrm{AP}$ with its neighboring bases, resulting in fluorescence quenching.

We next tested the T10-2AP DNA (Figure 2C). Interestingly, $\mathrm{Hg}^{2+}$ enhanced its fluorescence by $>7$-fold, while most other metals failed to trigger a fluorescence change. Its high specificity for $\mathrm{Hg}^{2+}$ can be explained by the formation of $\mathrm{T}-\mathrm{Hg}^{2+}-\mathrm{T}$ base pairs, reducing stacking between the $2 \mathrm{AP}$ and its adjacent thymines. The strong initial quenching of $2 \mathrm{AP}$ by thymine ( $98 \%)$ also gives a large room for signal enhancement. 
Finally for the C10-2AP DNA, $\mathrm{Ag}^{+}$produced the strongest fluorescence enhancement followed by $\mathrm{Hg}^{2+}$ (Figure 2D). The effect of $\mathrm{Ag}^{+}$can be explained by formation of the $\mathrm{C}-\mathrm{Ag}^{+}-\mathrm{C}$ complex (Ono et al. 2008). It was previously reported that $\mathrm{Ag}^{+}$can be chelated by pyrimidine bases in general (Urata et al. 2011), but we did not see its signal in the T10-2AP DNA. On the other hand, $\mathrm{Hg}^{2+}$ induced a strong signal in the poly-C DNA, suggesting that cytosine is also a ligand for $\mathrm{Hg}^{2+}$. Note that for all these experiments, we used only $0.1 \mu \mathrm{M}$ DNA. Metal ions at 2 $\mu \mathrm{M}$ were in large excess. The C10-2AP DNA has much higher selectivity for $\mathrm{Ag}^{+}$over $\mathrm{Hg}^{2+}$ at lower metal concentrations (vide infra).
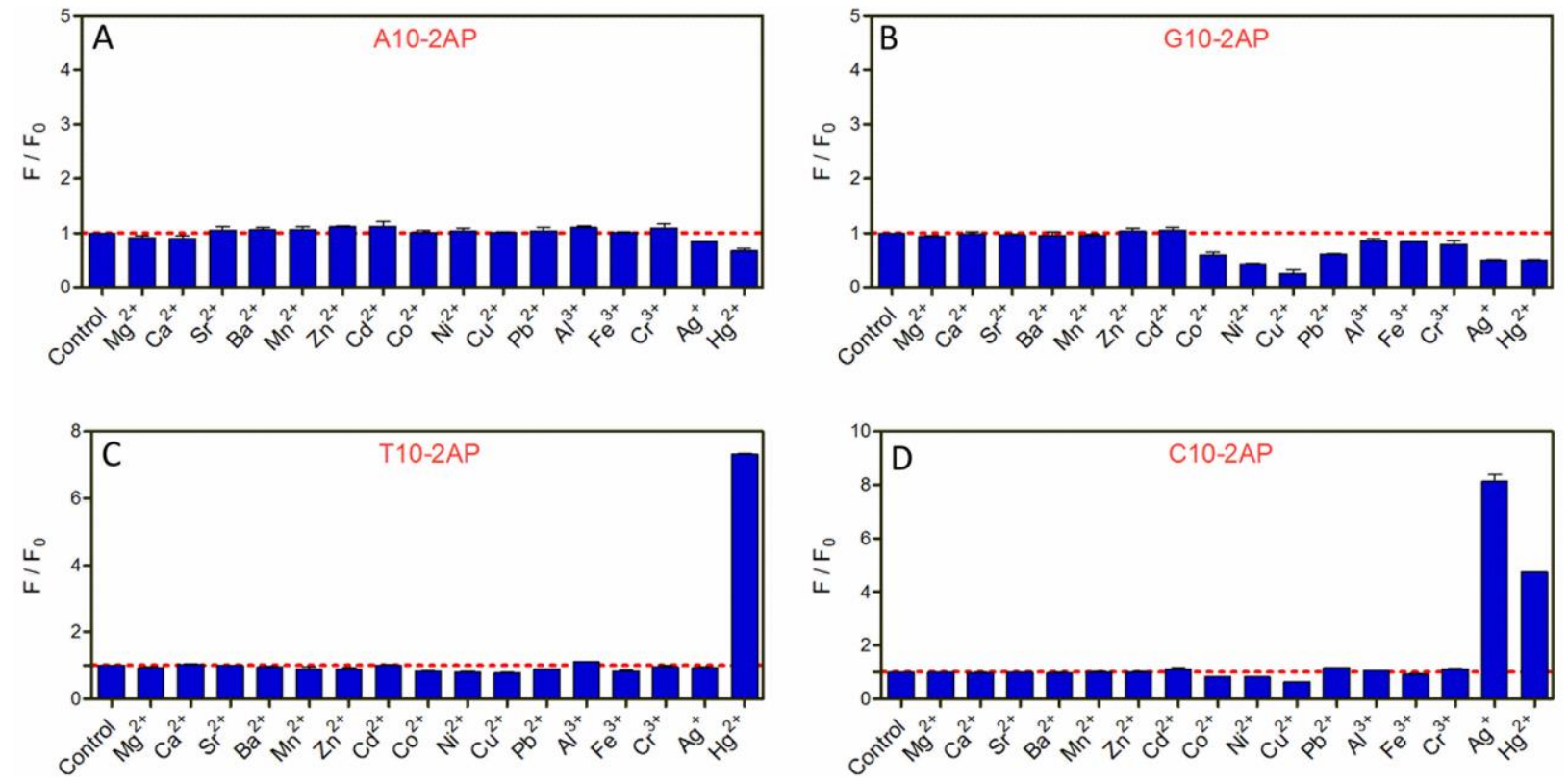

Figure 2. The relative fluorescence change of $0.1 \mu \mathrm{M}$ (A) A10-2AP, (B) G10-2AP, (C) T10-2AP and (D) C10-2AP DNA after adding $2 \mu \mathrm{M}$ various metal ions.

3.4. $\mathrm{Hg}^{2+}$ detection using T10-2AP DNA. With these probes, we might detect $\mathrm{Hg}^{2+}$ and $\mathrm{Ag}^{+}$. We next aim to test the sensitivity for their detection. The above studies indicate that T10-2AP is 
the best probe for $\mathrm{Hg}^{2+}$. A scheme of the $\mathrm{T}-\mathrm{Hg}^{2+}-\mathrm{T}$ complex is drawn in Figure $3 \mathrm{~A}$, and the detection scheme is presented in Figure 3B, where folding of the DNA relaxes the 2AP base stacking and enhances its fluorescence.

The fluorescence gradually increased at higher $\mathrm{Hg}^{2+}$ concentrations (Figure 3C). We further plotted the peak intensity at $370 \mathrm{~nm}$ against $\mathrm{Hg}^{2+}$ concentration (Figure 3D). A sigmoidal binding curve was obtained, suggesting metal binding cooperatively. The signaling kinetics were measured with $400 \mathrm{nM} \mathrm{Hg}^{2+}$ (inset of Figure 3E). Although the majority of signal increase occurred in the first $30 \mathrm{sec}$ (the time we used for collecting the data in Figure 3D), there is a slower phase taking a few minutes to finish.

Next, we also tested the effect of DNA length using a longer DNA containing 11 potential $\mathrm{T}-\mathrm{Hg}^{2+}-\mathrm{T}$ pairing bases (named T22-2AP, Figure S1). However, this longer probe is about 10 times less sensitive than the T10-2AP, possibly due to misfolding and the requirement of more $\mathrm{Hg}^{2+}$ to fold. We did not try even shorter DNA since five base pairs are typically required to form a stable hairpin. Therefore, our current probe is optimal for $\mathrm{Hg}^{2+}$ sensing.

With the T10-2AP probe, a roughly linear response was observed with up to $400 \mathrm{nM}$ $\mathrm{Hg}^{2+}$ (Figure 4D, inset). Based on the $3 \sigma /$ slope calculation ( $\sigma=$ background variation in the absence of $\mathrm{Hg}^{2+}$ ), the detection limit is $3 \mathrm{nM} \mathrm{Hg}^{2+}$, below the maximum level of mercury (10 $\left.\mathrm{nM}\right)$ permitted by the U.S. Environmental Protection Agency (U.S. EPA) for drinking water. With $800 \mathrm{nM} \mathrm{Hg}^{2+}$, the fluorescence enhancement reached nearly 14-fold (Figure 3D), indicating a high sensitivity. Such strong 2AP fluorescence enhancement was only observed in nuclease assays, where the 2AP was completely released from the DNA after enzymatic digestion (Su et al. 2012; Zhang et al. 2014). Some other enzymes, such as the EcoRI DNA methyltransferase, 
can disrupt base stacking and even flip DNA bases; they can also achieve a significant fluorescence increase (Allan and Reich 1996). Therefore, we suspect that the 2AP base here might also flip from being base stacked to solvent exposed after $\mathrm{Hg}^{2+}$ binding. In most other systems, the enhancement was much less. The closet aptamer system achieved 5-10 fold enhancement for protein detection (Katilius et al. 2006). Detection of small molecules using 2AP has not achieved such high sensitivity. For example, even with engineered basic sites, only a signal-off sensor was reported for theophylline detection ( $\mathrm{Li}$ et al. 2009a). While a signal-on aptasensor was reported using the structure-switching design, the fluorescence increase was less than 2-fold (Li and Ho 2008).

We further studied sensor specificity against various metal ions at $(0.2 \mu \mathrm{M}$ and $2 \mu \mathrm{M}$, Figure 3E). Among the tested metal ions, only $\mathrm{Hg}^{2+}$ showed an obvious fluorescence increase at both concentrations, further confirming a high selectivity towards $\mathrm{Hg}^{2+}$. We noticed that with 2 $\mu \mathrm{M} \mathrm{Hg}{ }^{2+}$, the fluorescence enhancement was only $\sim 7$-fold, less than the 14-fold achieved with $0.8 \mu \mathrm{M} \mathrm{Hg}^{2+}$ (Figure 3D, E), which is explained by that high concentrations of $\mathrm{Hg}^{2+}$ can nonspecifically quench the 2AP fluorescence (Figure 1E). 

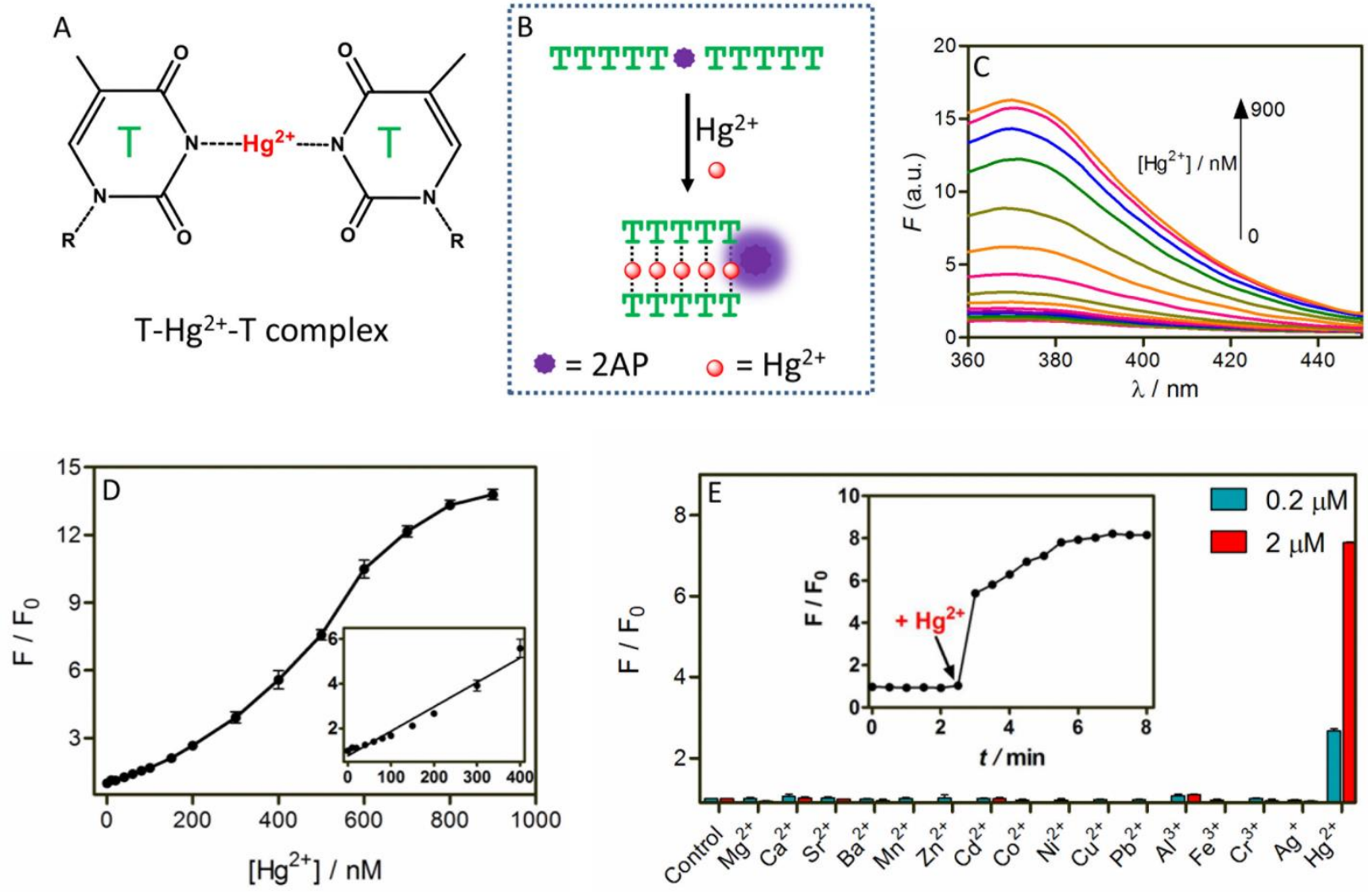

Figure 3. (A) The structure of a $\mathrm{T}-\mathrm{Hg}^{2+}-\mathrm{T}$ complex. (B) A scheme showing the fluorescence increase of the T10-2AP DNA by $\mathrm{Hg}^{2+}$. (C) The fluorescence spectra of the $\mathrm{Hg}^{2+}$ sensor with increasing $\mathrm{Hg}^{2+}$ concentrations. (D) Sensor response as a function of $\mathrm{Hg}^{2+}$ concentration. Inset: linear fluorescence enhancement at low $\mathrm{Hg}^{2+}$ concentrations. (E) Sensor specificity tested with 0.2 and $2 \mu \mathrm{M}$ various metal ions. Inset: the signaling kinetics of the sensor with $400 \mathrm{nM} \mathrm{Hg}^{2+}$.

3.5. Highly robust $\mathrm{Hg}^{2+}$ sensing. To test the effect of buffer conditions, we next measured the sensor response at different $\mathrm{pH}$ values. The sensitivity is higher for $\mathrm{Hg}^{2+}$ at higher $\mathrm{pH}$ (Figure $\mathrm{S} 2 \mathrm{~A}$ ). On the other hand, the fluorescence intensity of free 2AP and T10-2AP are insensitive to $\mathrm{pH}$ in the absence of $\mathrm{Hg}^{2+}$. Therefore, the $\mathrm{Hg}^{2+}$ sensor works better at higher $\mathrm{pH}$ (Figure $\mathrm{S} 2 \mathrm{~B}$ ), 
which is attributable to the required deprotonation of $\mathrm{N} 3$ in thymine facilitating $\mathrm{T}-\mathrm{Hg}^{2+}-\mathrm{T}$ mismatch formation (Miyake et al. 2006).

For sensing in real water samples, one can easily adjust the $\mathrm{pH}$ by using a buffer, but it is more difficult to control or even measure the ionic strength. Since DNA is a polyanion that can be easily condensed at high salt concentrations, ionic strength usually severely affects DNAbased sensors. By reading the literature, while the $\mathrm{T}-\mathrm{Hg}^{2+}-\mathrm{T}$ binding mechanism has been extensively employed, few have addressed the ionic strength issue (Huang et al. 2016; Kiy et al. 2012). One popular signaling method is to label a fluorophore and a quencher respectively on the two ends of a thymine-rich DNA, so that $\mathrm{Hg}^{2+}$ binding can shorten the end-to-end distance and thus induce fluorescence quenching (Ono and Togashi 2004). We previously carefully studied the conformation of such DNA as a function of ionic strength, and observed non-specific DNA folding by salt, causing false positive signals (Kiy et al. 2012).

Herein, we measured our T10-2AP sensor response to $400 \mathrm{nM} \mathrm{Hg}^{2+}$ at different $\mathrm{NaNO}_{3}$ concentrations (Figure 4A). The best sensitivity was achieved with $60 \mathrm{mM} \mathrm{Na}^{+}$, and the variation was quite small (coefficient of variation $\sim 10 \%$ ). An important feature of this sensor design is that it contains only a single molecule and a single label. Its signaling depends mainly on the local base stacking environment of the 2AP base instead of DNA global folding. This can explain its robustness.

To have a full comparison, we also tested two more signaling strategies. First, a FAMlabeled DNA was adsorbed on graphene oxide (GO), resulting in quenched initial fluorescence. $\mathrm{Hg}^{2+}$ can induce DNA desorption and thus fluorescence enhancement (Figure 4B) ( $\mathrm{Lu}$ et al. 2016). In the second example, SYBR Green I (SG) was used to stain the DNA hairpin formed 
after adding $\mathrm{Hg}^{2+}$, which also significantly enhances the emission intensity (Figure 4C). Without $\mathrm{Hg}^{2+}$, the DNA has a random coiled structure and cannot enhance the SG emission. This is a cost-effective label-free method (Wang and Liu 2008). In both examples, we measured the signal in 0 and $100 \mathrm{mM} \mathrm{NaNO}$ (Figure 4D). The GO signaling enhanced from less than 3-fold in the absence of salt to over 10 -fold with $100 \mathrm{mM} \mathrm{NaNO}$, which is likely due to the adsorption between DNA and GO is affected by salt (Wu et al. 2011). On the other hand, $\mathrm{NaNO}_{3}$ strongly decreased the SG fluorescence attributable to a charge screening effect weakening DNA/SG interaction (Zipper et al. 2004), which affected both the initial background and the final signal after $\mathrm{Hg}^{2+}$ addition. Since the background fluorescence was affected more, the signaling also increased with $100 \mathrm{mM} \mathrm{NaNO}_{3}$. The robustness of the $2 \mathrm{AP}$ label is attributable its signaling being less dependent of DNA hybridization (or duplex formation), end-to-end distance change, or electrostatic interactions, while most other sensing strategies rely on these.

All these methods have an excellent sensitivity. Using $\mathrm{SG}, \mathrm{Hg}^{2+}$ can be detected down to $1.3 \mathrm{nM}$ (Wang and Liu 2008), which is better than that of the GO-based method (LOD = $20 \mathrm{nM}$ ) (Lu et al. 2016). Our 2AP sensor also achieved a detection limit of $3 \mathrm{nM}$. The main advantage of our sensor is its robustness. In addition, our detection process is much simpler, requiring just a simple mixing step, while other methods need to either pre-adsorb DNA probes on GO or further adding SG.

3.6. Sensor regeneration. For practical applications, sensors need to have a reversible responses to allow for continuous monitoring of the analyte concentration fluctuation. To test this, we employed iodide to modulate $\mathrm{Hg}^{2+}$ concentration. Iodide binds $\mathrm{Hg}^{2+}$ with extremely high affinity and it can reduce the free $\mathrm{Hg}^{2+}$ in solution. We started by adding $400 \mathrm{nM} \mathrm{Hg}^{2+}$ to the sensor, and a significant fluorescence increase was observed immediately. Five minutes later, $800 \mathrm{nM} \mathrm{I}^{-}$was 
added and the signal dropped back to the background level (Figure 4E). Further adding $\mathrm{Hg}^{2+}$ enhanced the fluorescence again, which demonstrated sensor reversibility. After a few cycles, the maximal fluorescence decreased progressively. This could be due to the accumulation of $\mathrm{HgI}_{2}$, which may non-specifically adsorb the DNA and quench the fluorescence.

3.7. Sensing in lake water. To test the sensor performance in real water samples, we collected water from Lake Huron. The final test solution consisted of $99 \%$ lake water and $1 \%$ the sensor containing buffer. When titrated this solution with different $\mathrm{Hg}^{2+}$ concentrations, a fluorescence increase similar to that in the pure water was observed (Figure 4F). The sensor can detect $\mathrm{Hg}^{2+}$ in the lake water up to $600 \mathrm{nM}$, with a detection limit of $8.4 \mathrm{nM} \mathrm{Hg}^{2+}$. Therefore, this sensor is useful for detecting $\mathrm{Hg}^{2+}$ in environmental water samples. 

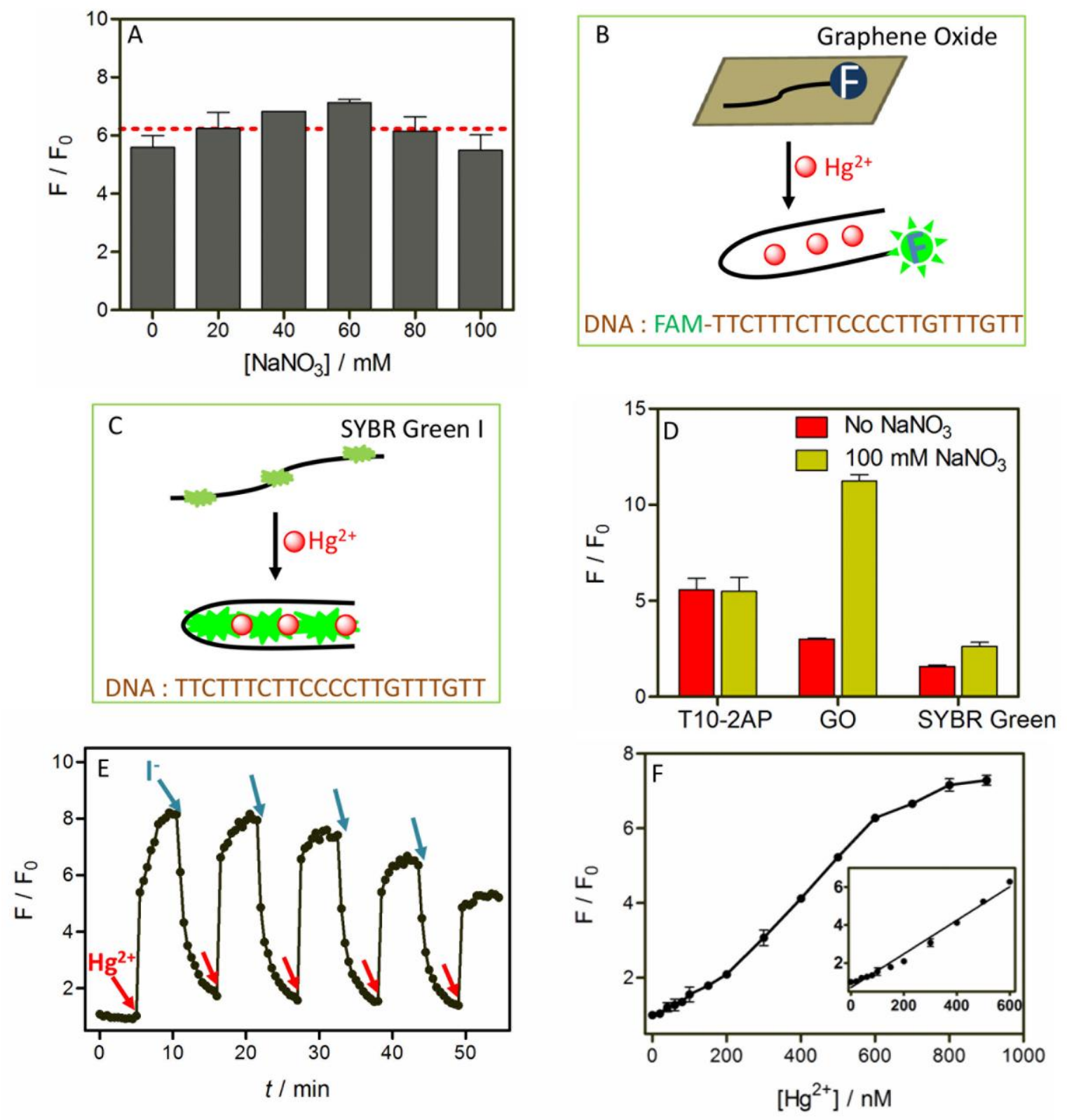

Figure 4. (A) The T10-2AP DNA sensor response with $400 \mathrm{nM} \mathrm{Hg}^{2+}$ under different $\mathrm{NaNO}_{3}$ concentrations. Schemes illustrating (B) GO-based and (C) SG-based sensors for $\mathrm{Hg}^{2+}$ detection. (D) Comparison the signaling of each sensor with $400 \mathrm{nM} \mathrm{Hg}^{2+}$ in the absence and presence of $100 \mathrm{mM} \mathrm{NaNO}$. (E) The T10-2AP sensor reversibility test. $\mathrm{Hg}^{2+}$ and $\mathrm{I}^{-}$were added at $400 \mathrm{nM}$ and $800 \mathrm{nM}$ each time, respectively. (F) The sensor response as a function of $\mathrm{Hg}^{2+}$ concentration 
in $99 \%$ of Lake Huron water. Inset: the fluorescence linearly increases at low $\mathrm{Hg}^{2+}$ concentrations.

3.8. $\mathrm{Ag}^{+}$detection using C10-2AP. Having demonstrated the use of $\mathrm{T} 10-2 \mathrm{AP}$ for $\mathrm{Hg}^{2+}$ detection, we next explored the $\mathrm{C} 10-2 \mathrm{AP}$ DNA for $\mathrm{Ag}^{+}$detection. The structure $\mathrm{C}-\mathrm{Ag}^{+}-\mathrm{C}$ is shown in Figure $5 \mathrm{~A}$, and the scheme of sensing is presented in Figure 5B, which is quite similar to that for $\mathrm{Hg}^{2+}$ detection described above. To test the sensor, we first measured the sensor fluorescence spectra before and after adding $700 \mathrm{nM} \mathrm{Ag}$, where a significant fluorescence increase was achieved (Figure 5C). A more careful titration showed that the fluorescence of the sensor increases gradually with increasing $\mathrm{Ag}^{+}$concentration (Figure 5D). The fluorescence reached a plateau with $\sim 500 \mathrm{nM} \mathrm{Ag}^{+}$, and this is consistent with each DNA binding five $\mathrm{Ag}^{+}$ions $(100 \mathrm{nM}$ DNA used). Under the same condition, the T10-2AP DNA needs $\sim 8 \mathrm{Hg}^{2+}$ to achieve saturated binding (Figure 3D). In this aspect, the $\mathrm{C}-\mathrm{Ag}^{+}-\mathrm{C}$ complex appears slightly more stable than the $\mathrm{T}-\mathrm{Hg}^{2+}-\mathrm{T}$ complex. In the range of $0-400 \mathrm{nM} \mathrm{Ag}$, the sensor has a linear response (inset of Figure 5D) with a detection limit of $3 \mathrm{nM} \mathrm{Ag}^{+}$, significantly lower than the toxic level described by the U.S. EPA for drinking water $(460 \mathrm{nM})$. Finally, we tested the sensor specificity with 2 and $0.2 \mu \mathrm{M}$ various metal ions (Figure 5E). It is interesting to note that the signal from $\mathrm{Hg}^{2+}$ was significantly lower at $0.2 \mu \mathrm{M}$ metal concentration (only about $20 \%$ of the $\mathrm{Ag}^{+}$signal), while at 2 $\mu \mathrm{M}$, it is over half of the $\mathrm{Ag}^{+}$signal. This is consistent with the selective binding of $\mathrm{Ag}^{+}$by cytosine (Ono et al. 2008; Ono et al. 2011). At much higher metal concentrations, however, $\mathrm{Hg}^{2+}$ can still show significant binding. 

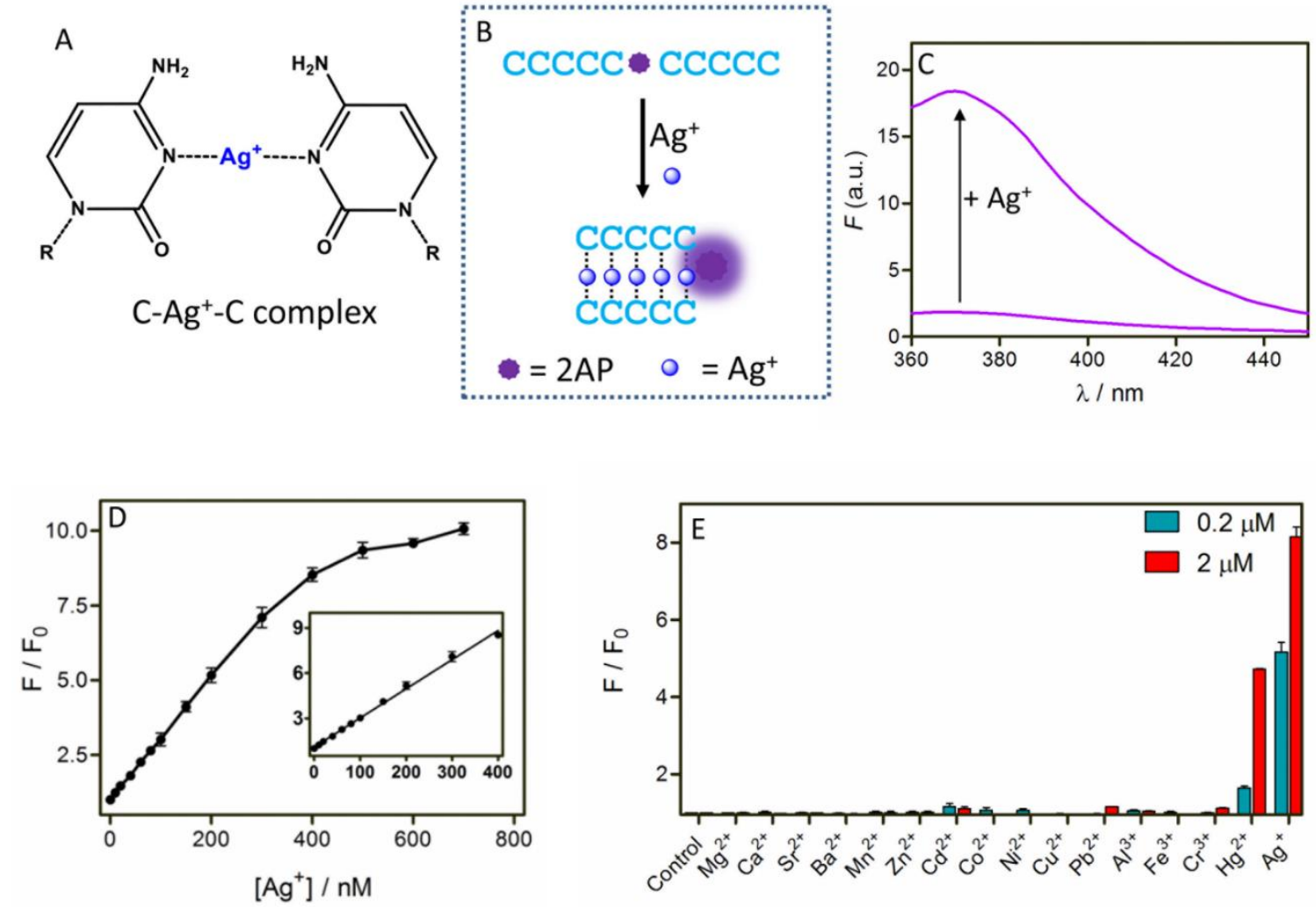

Figure 5. (A) The structure of $\mathrm{C}-\mathrm{Ag}^{+}-\mathrm{C}$ complex. (B) A scheme showing the fluorescence increase of the C10-2AP DNA caused by $\mathrm{Ag}^{+}$. (C) The fluorescence spectra of this sensor in absence and presence of $700 \mathrm{nM} \mathrm{Ag}^{+}$. (D) Sensor response as a function of $\mathrm{Ag}^{+}$concentration. Inset: sensor linear response at low $\mathrm{Ag}^{+}$concentrations. (E) Sensor specificity with 0.2 and $2 \mu \mathrm{M}$ of various metal ions.

\section{Conclusions.}

In summary, we reported the first heavy metal sensors using 2AP signaling. This comprehensive study has included all the four DNA homopolymers and most common metal ions. With this 
simple sensor design, we showed that $2 \mathrm{AP}$ is a highly robust fluorescent label in DNA. The advantage of $2 \mathrm{AP}$ is its sensitivity to the local base stacking environment and insensitivity to non-specific DNA condensation. Therefore, it can solve the ionic strength dependent problem for DNA-based sensors. W compared the 2AP-based sensors with three other signaling strategies using the same $\mathrm{Hg}^{2+}$ recognition chemistry. Taken together, this work has provided robust sensors for $\mathrm{Hg}^{2+}$ and $\mathrm{Ag}^{+}$, and the same design method is likely applicable to other analytes.

\section{Acknowledgement}

This work is supported by the University of Waterloo, the Natural Sciences and Engineering Research Council of Canada (NSERC), Foundation for Shenghua Scholar of Central South University and the National Natural Science Foundation of China (Grant No. 21301195). W.Z. is supported by the Fellowship from the China Scholarship Council (CSC, Grant No. 201406370116).

Supporting Information Available: The following files are available free of charge.

Effect of DNA length and pH value on sensor performance.

\section{References}

1. Allan, B.W., Reich, N.O., 1996. Biochemistry 35, 14757-14762.

2. Clarkson, T.W., Magos, L., Myers, G.J., 2003. N. Engl. J. Med. 349, 1731-1737. 
3. Hall, K.B., 2009. Chapter 13 - 2-Aminopurine as a Probe of RNA Conformational Transitions. Meth. Enzymol., pp. 269-285. Academic Press.

4. Hollenstein, M., Hipolito, C., Lam, C., Dietrich, D., Perrin, D.M., 2008. Angew. Chem., Int. Ed. 47, 4346 - 4350.

5. Huang, P.-J.J., Liu, J., 2014. Anal. Chem. 86, 5999-6005.

6. Huang, P.-J.J., van Ballegooie, C., Liu, J., 2016. Analyst 141, 3788-3793.

7. Huang, P.-J.J., Wang, F., Liu, J., 2015. Anal. Chem. 87, 6890-6895.

8. Jones, A.C., Neely, R.K., 2015. Quarterly Reviews of Biophysics 48, 244-279.

9. Katilius, E., Katiliene, Z., Woodbury, N.W., 2006. Anal. Chem. 78, 6484-6489.

10. Kelley, S.O., Barton, J.K., 1999. Science 283, 375-381.

11. Kim, H.N., Ren, W.X., Kim, J.S., Yoon, J., 2012. Chem. Soc. Rev. 41, 3210-3244.

12. Kiy, M.M., Jacobi, Z.E., Liu, J., 2012. Chem. Eur. J 18, 1202-1208.

13. Larsen, O.F.A., van Stokkum, I.H.M., de Weerd, F.L., Vengris, M., Aravindakumar, C.T., van Grondelle, R., Geacintov, N.E., van Amerongen, H., 2004. Phys. Chem. Chem. Phys. 6, 154-160.

14. Lee, J., Park, J., Hee Lee, H., Park, H., Kim, H.I., Kim, W.J., 2015. Biosens. Bioelectron. 68, $642-647$.

15. Li, D., Song, S.P., Fan, C.H., 2010. Acc. Chem. Res. 43, 631-641.

16. Li, D., Wieckowska, A., Willner, I., 2008. Angew. Chem. Int. Ed. 47, 3927-3931.

17. Li, M., Sato, Y., Nishizawa, S., Seino, T., Nakamura, K., Teramae, N., 2009a. J. Am. Chem. Soc. 131, 2448-2449.

18. Li, N., Ho, C.-M., 2008. J. Am. Chem. Soc. 130, 2380-2381.

19. Li, T., Shi, L., Wang, E., Dong, S., 2009b. Chem. Eur. J 15, 3347-3350. 
20. Lin, Y.-H., Tseng, W.-L., 2009. Chem. Commun., 6619-6621.

21. Liu, J., Cao, Z., Lu, Y., 2009. Chem. Rev. 109, 1948-1998.

22. Lu, C., Jimmy Huang, P.-J., Ying, Y., Liu, J., 2016. Biosens. Bioelectron. 79, 244-250.

23. Martí, A.A., Jockusch, S., Li, Z., Ju, J., Turro, N.J., 2006. Nucleic Acids Res. 34, e50.

24. Miyake, Y., Togashi, H., Tashiro, M., Yamaguchi, H., Oda, S., Kudo, M., Tanaka, Y., Kondo, Y., Sawa, R., Fujimoto, T., Machinami, T., Ono, A., 2006. J. Am. Chem. Soc. 128, 2172.

25. Morishita, K., MacLean, J.L., Liu, B., Jiang, H., Liu, J., 2013. Nanoscale 5, 2840-2849.

26. Nazarenko, I., Pires, R., Lowe, B., Obaidy, M., Rashtchian, A., 2002. Nucleic Acids Res. 30, 2089-2195.

27. Nolan, E.M., Lippard, S.J., 2008. Chem. Rev. 108, 3443-3480.

28. Nutiu, R., Li, Y., 2003. J. Am. Chem. Soc. 125, 4771-4778.

29. Ono, A., Cao, S., Togashi, H., Tashiro, M., Fujimoto, T., Machinami, T., Oda, S., Miyake, Y., Okamoto, I., Tanaka, Y., 2008. Chem. Commun., 4825-4827.

30. Ono, A., Togashi, H., 2004. Angew. Chem., Int. Ed. 43, 4300-4302.

31. Ono, A., Torigoe, H., Tanaka, Y., Okamoto, I., 2011. Chem. Soc. Rev. 40, 5855-5866.

32. Rachofsky, E.L., Seibert, E., Stivers, J.T., Osman, R., Ross, J.B.A., 2001. Biochemistry 40, 957-967.

33. Ratte, H.T., 1999. Environ. Toxicol. Chem. 18, 89-108.

34. Saran, R., Liu, J., 2016. Anal. Chem. 88, 4014-4020.

35. Shiang, Y.-C., Huang, C.-C., Chen, W.-Y., Chen, P.-C., Chang, H.-T., 2012. J. Mater. Chem. 22, 12972-12982.

36. Soulière, M.F., Haller, A., Rieder, R., Micura, R., 2011. J. Am. Chem. Soc. 133, 1616116167. 
37. Su, X., Zhu, X., Zhang, C., Xiao, X., Zhao, M., 2012. Anal. Chem. 84, 5059-5065.

38. Tanaka, Y., Oda, S., Yamaguchi, H., Kondo, Y., Kojima, C., Ono, A., 2007. J. Am. Chem. Soc. 129, 244.

39. Tyagi, S., Kramer, F.R., 1996. Nat. Biotechnol. 14, 303-308.

40. Urata, H., Yamaguchi, E., Nakamura, Y., Wada, S.-i., 2011. Chem. Commun. 47, 941-943.

41. Wang, H., Yang, R.H., Yang, L., Tan, W.H., 2009a. ACS Nano 3, 2451-2460.

42. Wang, J., Liu, B., 2008. Chem. Commun., 4759-4761.

43. Wang, K.M., Tang, Z.W., Yang, C.Y.J., Kim, Y.M., Fang, X.H., Li, W., Wu, Y.R., Medley, C.D., Cao, Z.H., Li, J., Colon, P., Lin, H., Tan, W.H., 2009b. Angew. Chem. Int. Ed. 48, 856-870.

44. Wang, Z., Lee, J.H., Lu, Y., 2008. Chem. Commun., 6005-6007.

45. Wu, M., Kempaiah, R., Huang, P.-J.J., Maheshwari, V., Liu, J., 2011. Langmuir 27, 27312738.

46. Zhan, S., Wu, Y., Wang, L., Zhan, X., Zhou, P., 2016. Biosens. Bioelectron. 86, 353-368.

47. Zhang, P., Zhang, J., Wang, C., Liu, C., Wang, H., Li, Z., 2014. Anal. Chem. 86, 1076-1082.

48. Zhang, X.-B., Kong, R.-M., Lu, Y., 2011. Annu. Rev. Anal. Chem. 4, 105-128.

49. Zhou, Y., Tian, X.-L., Li, Y.-S., Zhang, Y.-Y., Yang, L., Zhang, J.-H., Wang, X.-R., Lu, S.Y., Ren, H.-L., Liu, Z.-S., 2011. Biosens. Bioelectron. 30, 310-314.

50. Zipper, H., Brunner, H., Bernhagen, J., Vitzthum, F., 2004. Nucleic Acids Res. 32, e103. 